\title{
Design, Simulation and Stability Analysis of Wind-PV-Diesel Hybrid Power System Using ETAP
}

\author{
Md Saleh Ebn Sharif ${ }^{1, ~ *, ~ M d ~ M o n o w e r ~ Z a h i d ~ K h a n ², ~ M d ~ M o n i r u z z a m a n ~}{ }^{1}$, Anamika Bose ${ }^{1}$ \\ ${ }^{1}$ Department of Electrical and Electronic Engineering, Bangladesh University of Engineering and Technology, Dhaka, Bangladesh \\ ${ }^{2}$ School of Electrical and Electronic Engineering, University of Manchester, Manchester, England
}

\section{Email address:}

Saleh.ebn.sharif@gmail.com (Md S. E. Sharif)

${ }^{*}$ Corresponding author

\section{To cite this article:}

Md Saleh Ebn Sharif, Md Monower Zahid Khan, Md Moniruzzaman, Anamika Bose. Design, Simulation and Stability Analysis of Wind-PV-Diesel Hybrid Power System Using ETAP. American Journal of Modern Energy.

Vol. 3, No. 6, 2017, pp. 121-130. doi: 10.11648/j.ajme.20170306.12

Received: October 13, 2017; Accepted: November 3, 2017; Published: November 25, 2017

\begin{abstract}
Nowadays, the hybrid power system is getting popular because of its advantage of renewable integration to the traditional power grid. In this paper, a review of the hybrid power system is presented and detailed analysis of steady state \& transient stability is performed. For detailed analysis, IEEE 9 bus system has been adopted and modified for this study. The proposed isolated hybrid system consists of the wind turbine, solar PV array, energy storage system, a backup diesel generator and battery bank to study the system analysis. The hybrid wind-solar electric power system was modeled in ETAP software. The variation in power angle of the system after a three-phase fault is studied. The whole system also is studied and simulated for different case studies and combination of some outages to study the impact of disturbance in system stability.
\end{abstract}

Keywords: Hybrid Power System, Microgrid, ETAP, Renewable Integration, Stability Analysis, Rotor Angle, Energy Storage, Solar Energy

\section{Introduction}

Day by day the need for renewable energy resources is increasing and this increasing demand for energy has set researchers to adopt new methodologies. Now, it is a very well known topic that renewable energy sources are going to take crucial places in the future energy system. This increasing demand and future plan for new energy system have encouraged scientist and engineers for research in the hybrid energy system. Due to environmental impact and implementation of energy conservation policies, all countries are taking steps towards reducing greenhouse gas emissions and lessening the use of fossil fuel. Moreover, fossil fuel sources are unevenly distributed on the earth and in particular location if there is an abundance of other natural resources that can be utilized as sources of renewable energy. As a result, researchers are thinking about utilizing and mixing renewable and non- renewable resources for meeting up the up growing energy demand hence the idea of the hybrid energy system came [1].
In a hybrid system, there can be a number of power generation resources, for example, wind turbines, solar photovoltaic cell, small hydro system, diesel generator etc. The hybrid system is capable to provide electricity supply small system, a small community to very large areas including remote island grid [1]. In recent, due to remote power transmission constraint, the hybrid power system is getting popular in many remote communities in developing countries. In remote areas, transmission and distribution expansion are very costly as well as transportation of diesel fuel, coal, gas transmission are very expensive hence conventional energy sources cannot provide low-cost electricity to remote locality [2]. The use of renewable power generation and distributed energy system offers a solution to this problem which can reduce use of fossil fuel, cleaner generation and cheap electricity. However, different renewable sources and diesel system are providing electricity at different rates. Combining these all sources, there is a need for optimization and unit commitment methodology to get cheaper electricity based on the availability of energy sources [2]. Wind sources and solar system changes in a timely pattern so it will not give 
continuous availability of energy system. As a result in absence of renewable sources hybrid grid sometimes needs to rely on fossil sources. In a hybrid microgrid, power generation systems based on diesel, HFO, gas are supplying power at different tariff [3]. So, as a whole and considering the only fossil fuel-based generation, these generation systems also need a unit commitment rules [2], [3]. This system combines sources and saves energy when fissile based generation is absent to ensure a continuous supply of power and whenever generation is required. The objectives of this project are to design a hybrid microgrid which includes wind turbine, solar system, energy storage system \&backup diesel generators and study the stability of system considering different generation system's availability/downtime and load conditions. The remainder of this paper is organized as follows. The second section presents descript of the hybrid power system. The third describes the classification of the hybrid power system. The fourth section describes transient stability analysis and simulation methodology. The fifth section illustrates the detailed design, analysis and case studies of the hybrid system.

\section{Hybrid Power System}

The hybrid power system is a system in which two or more sources from different renewable energy (solar-thermal, wind, solar-photovoltaic, biomass, geothermal, hydropower, etc.) are integrated to provide electricity or heat, or both, to the consumers. The most popular form of the hybrid system consists of diesel generators and wind turbines [2]. Because of the supply pattern of different renewable energy sources as they are depending on weather, they have intermittency. It is can be possible to achieve a better overall supply pattern by integrating two or more generation sources and also including a form of energy storage. By adopting this strategy of the combination of renewable sources and energy storage, energy supply can be made less intermittent, or more continuous [4],[5]. In order to increase the duration of energy autonomy, combining the renewable hybrid system with batteries as a storage system will make optimal use of the available renewable energy resource and this, in turn, can guarantee high supply reliability. In order to deal with worst weather condition and supply the required load demand at this weather condition, the strategy of using large energy storage system is very expensive [5]. It is cheaper to supply at peaks demand condition. There are numerous possible applications for hybrid power systems. The most common examples are [7]:

a. Remote AC network,

b.Distributed generation applications in a conventional utility network, and

c. Isolated or special purpose electrical loads.

The classic example of the hybrid energy system is the remote, diesel-powered AC network. The basic goal is to decrease the amount of fuel consumed by diesel generators and to decrease the number of hours that they operate. The first addition to hybridize the system is to add another type of generator, normally using a renewable source. These renewable generators are most commonly wind turbines or photovoltaic panels. However, that simply adding another generator is not sufficient to produce the desired results. Accordingly, most hybrid systems also include one or more of the following to modernize the system: supervisory control system, short-term energy storage, and load management [8]. Figure 1 shows an example of the hybrid power system. Components for electricity generation can utilize renewable energy sources like wind turbines, photovoltaic, solar thermal, hydropower, wave power or biomass power stations. The wind-solar hybrid system mainly consists of one or two generators along with PV panels of suitable capacity, connected with charge controller, inverter, battery bank, etc. to supply AC power.

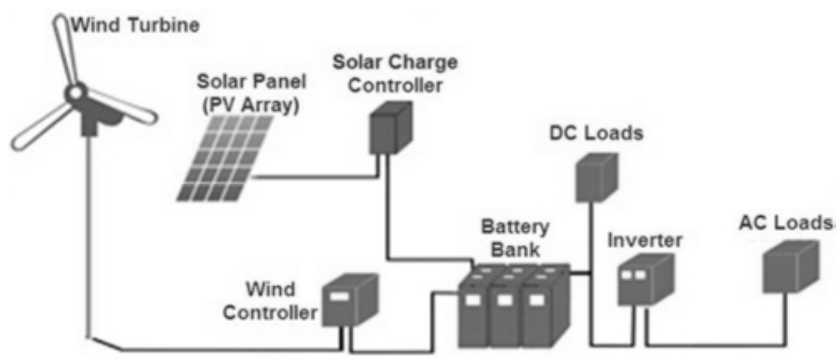

Figure 1. Wind-Solar Hybrid Power System.

The main components of hybrid power systems are described below [5-8]:

a) PV Module (PV Array): A number of PV panels connected in series or/and in parallel giving a DC output out of the incident irradiance. Orientation and tilt of these panels are important design parameters, as well as shading from surrounding obstructions.

b) Wind turbine: This is installed on top of a tall tower, uses kinetic energy from the wind and converts it to electricity that is compatible with a home's electrical system.

c) Hybrid controller: This is designed to integrate all three (the DC power from the solar array, the AC/DC or three-phase $\mathrm{AC}$ from the wind turbine, and the power from the backup) [9].

d) Energy storage: Energy storage is often useful in hybrid energy systems. Energy storage can have two main functions. First of all, it can be used to adapt to a mismatch between the electrical load and the renew-able energy resource. Second, it can be used to facilitate the control and operation of the overall system. There are basically two types of energy storage, convertible and end use. Convertible storage is that which can readily be converted back to electricity. End-use storage can be applied to a particular end-use requirement but may not readily be converted back to electricity [7-8].

e) Inverter: A power converter that inverts the DC power from the panels into AC power.

Advantages of Hybrid Systems:

a) Hybrid systems can address limitations in terms of fuel flexibility, efficiency, reliability, emissions and / or economics.

b) The possibility to combine two or more renewable energy sources based on the natural local potential of the 
users Environmental protection, especially in terms of $\mathrm{CO}_{2}$ emissions reduction.

c) Low cost - wind energy, and also solar energy can be competitive with nuclear, coal and gas especially considering possible future cost trends for fossil and nuclear energy.

d) Costs are predictable and not influenced by fuel price fluctuations, although fluctuations in the price of batteries will be an influence where these are incorporated.

e) Achieving higher reliability can be accomplished with redundant technologies and/or energy storage. Some hybrid systems typically include both, which can simultaneously improve the quality and availability of power.

\section{Types of Hybrid System}

The major types of hybrid power system are shortly described in below.

Central Grid Connected Hybrid Systems: If the hybrid system is connected to a central utility grid, as in a DG application, then the design is simplified to a certain degree and the number of components may be reduced. This is because the voltage and frequency are set by the utility system and need not be controlled by the hybrid system. In addition, the grid normally provides the reactive power [15]. When more energy is required than supplied by the hybrid system the deficit can be in general be provided by the utility. Similarly, any excess produced by the hybrid system can be absorbed by the utility $[8,18]$. In some cases, the grid does not act as an infinite bus, however. It is then said to be weak.

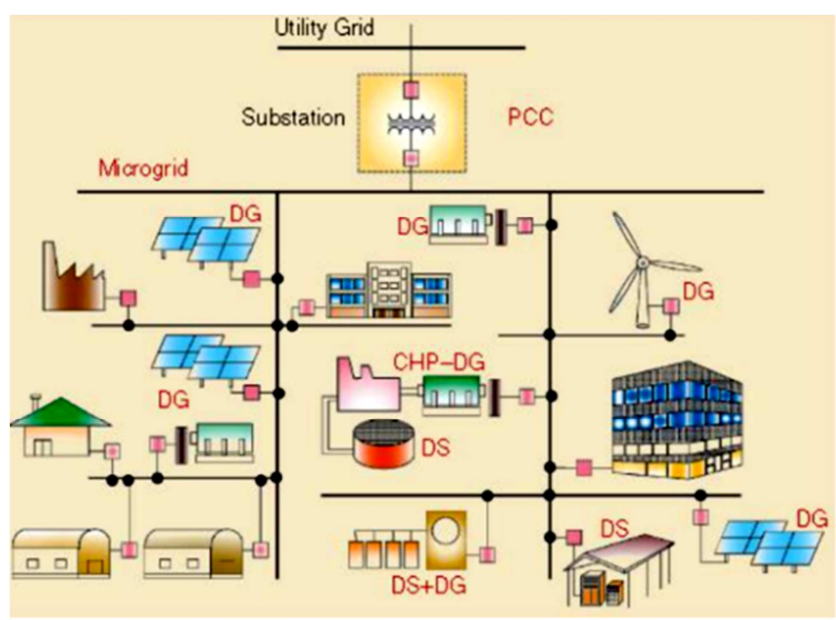

Figure 2. Grid connected hybrid system.

Isolated Grid Hybrid Systems: Isolated grid hybrid systems differ in many ways from most of those connected to a central grid. First, they must be able to provide for all the energy that is required at any time on the grid or find a graceful way to shed load when they cannot [16]. They must be able to set the grid frequency and control the voltage. The latter requirement implies that they must be able to provide reactive power as needed [9]. Under certain conditions, renewable generators may produce energy in excess of what is needed. This energy must be dissipated in some way so as not to introduce instabilities into the system [16].

Special Purpose Hybrid Systems: Some hybrid systems are used for a dedicated purpose, without use of real distribution network. These special purposes could include water pumping, aerating, heating, desalination, or running grinders or other machinery [17]. Design of these systems is usually such that system frequency and voltage control are not major issues, nor is excess power production. In those cases where energy may be required even when renewable source be temporarily unavailable, a more conventional generator may be provided [18]. Renewable generators in small isolated systems typically do not run in parallel with a fossil fuel generator.

\section{Transient Stability \& Rotor Angle Stability}

The stability of a system refers to the ability of a system to return back to its steady state when subjected to a disturbance. As mentioned before, power is generated by synchronous generators that operate in synchronism with the rest of the system. A generator is synchronized with a bus when both of them have same frequency, voltage and phase sequence. We can thus define the power system stability as the ability of the power system to return to steady state without losing synchronism. Usually power system stability is categorized into Steady State, Transient and Dynamic Stability. Steady State Stability studies are restricted to small and gradual changes in the system operating conditions. In this we basically concentrate on restricting the bus voltages close to their nominal values. We also ensure that phase angles between two buses are not too large and check for the overloading of the power equipment and transmission lines. These checks are usually done using power flow studies. Transient Stability involves the study of the power system following a major disturbance [10]. Following a large disturbance the synchronous alternator the machine power (load) angle changes due to sudden acceleration of the rotor shaft. The objective of the transient stability study is to ascertain whether the load angle returns to a steady value following the clearance of the disturbance [12]. The ability of a power system to maintain stability under continuous small disturbances is investigated under the name of Dynamic Stability (also known as small-signal stability). These small disturbances occur due random fluctuations in loads and generation levels. In an interconnected power system, these random variations can lead catastrophic failure as this may force the rotor angle to increase steadily [10]-[14].

As it is commonly referred to, is concerned with the ability of the power system to maintain synchronism when subjected to a severe transient disturbance. The resulting system response involves large excursions of generator rotor angles and is influenced by the nonlinear power-angle relationship. Transient stability depends on both the initial operating state 
of the system and the severity of the disturbance. Usually, the disturbance alters the system such that the post-disturbance steady state operation will be different from that prior to the disturbance [14]. Instability is in the form of aperiodic drift due to insufficient synchronizing torque, and is referred to as first swing stability [13].

\section{Hybrid Wind-Solar System Simulation}

This chapter describes the methodology to implement the Hybrid Wind-Solar System and simulate in ETAP software program. The Wind - Solar- Diesel Hybrid power system was tested on a simple network. An IEEE 9-Bus test system consists of initially of nine busses, three generators with total capacity of 519.5 MW \& a total load of 330.618 MW is taken as test network. The IEEE 9-Bus system is slightly customized to simulate the Solar-Wind Hybrid system shown in Figure 3. The modified network consists of two generators - G1 which operates as a voltage controlled generator and the backup generator and G2 which operates as the battery bank since it operates as a swing generator to supply the load in case of not enough power from other sources and a combination of wind turbines represented by one 163.2 MW wind turbine connected to bus-7 via bus-11 and a PV panel represented simply by a battery (2552 AH, $143 \mathrm{~V}$ ) which connected to the bus-9 through an inverter (inv1). Inv 1 is placed between bus 10 and dcbus1.

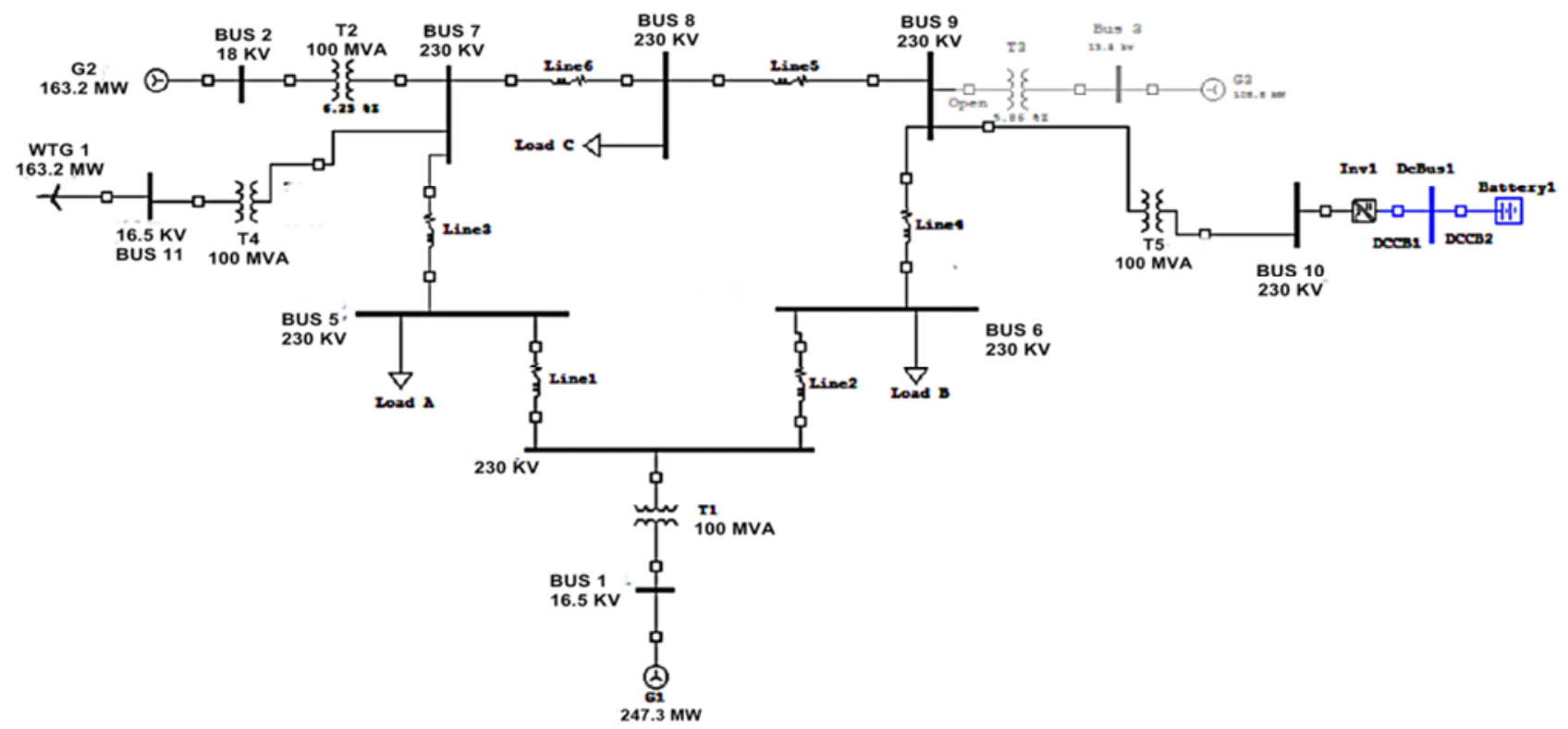

Figure 3. The PV-Wind-Diesel Hybrid System.

Some assumptions are made in this simulation, for example, wind and PV system operate at their full rated capacity. Generator G2 is assumed to be operated as a swing generator to represent the battery bank. For the analysis of the detailed system, simulation will be performed under different operating condition of generators, PV panel, wind turbine and energy storage.

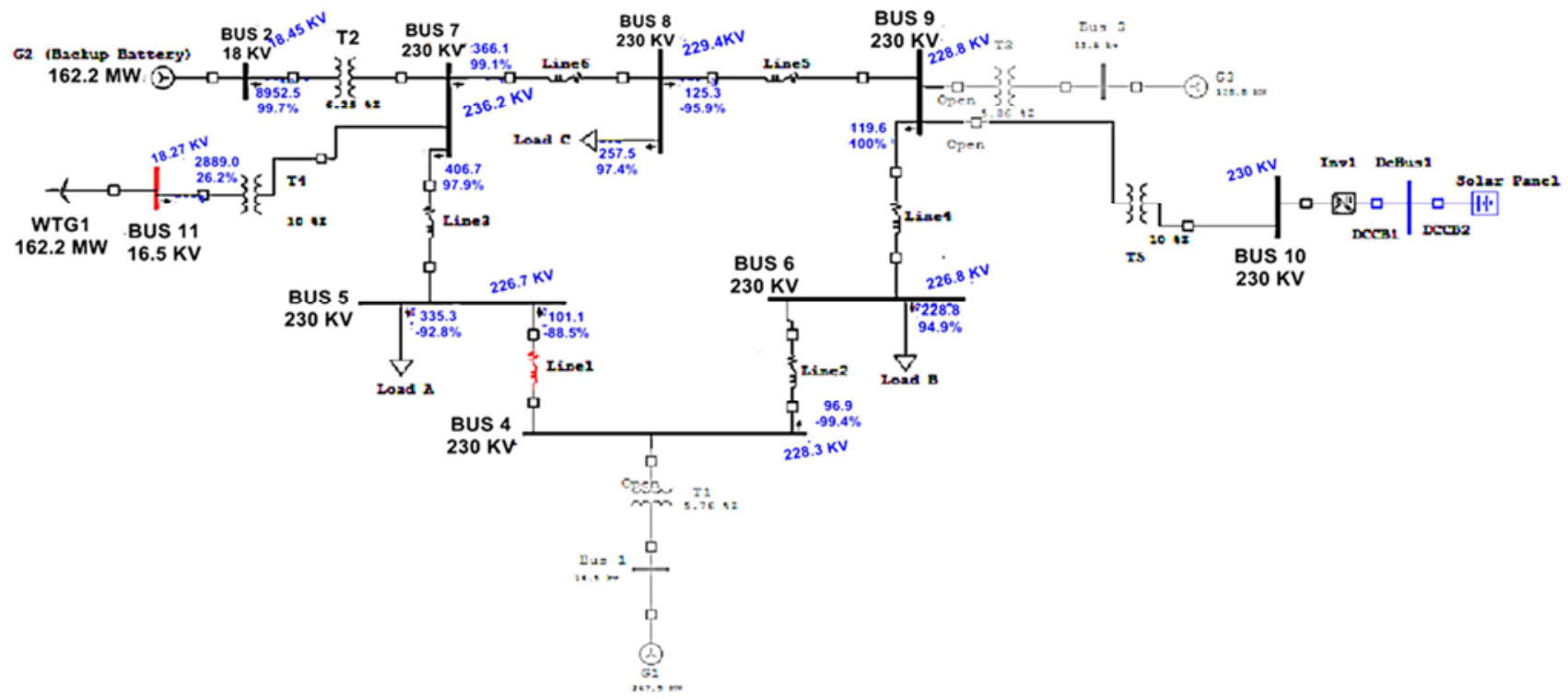

(a) Case-1: WTG and Battery Bank are active 


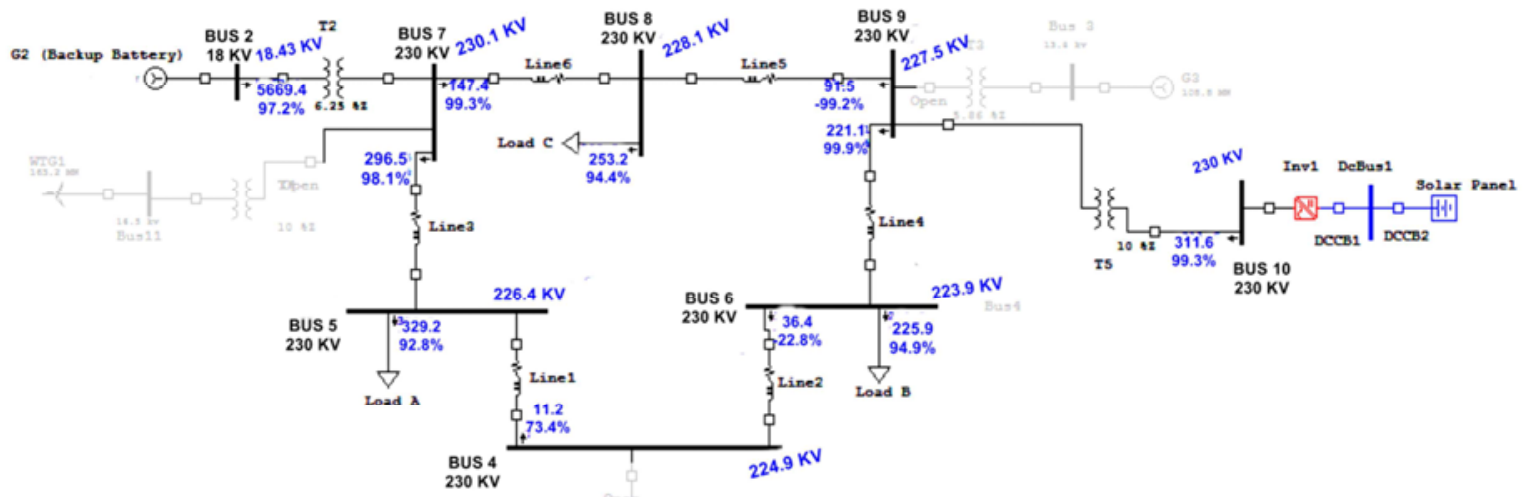

(b) Case-2: PV system and Battery are active

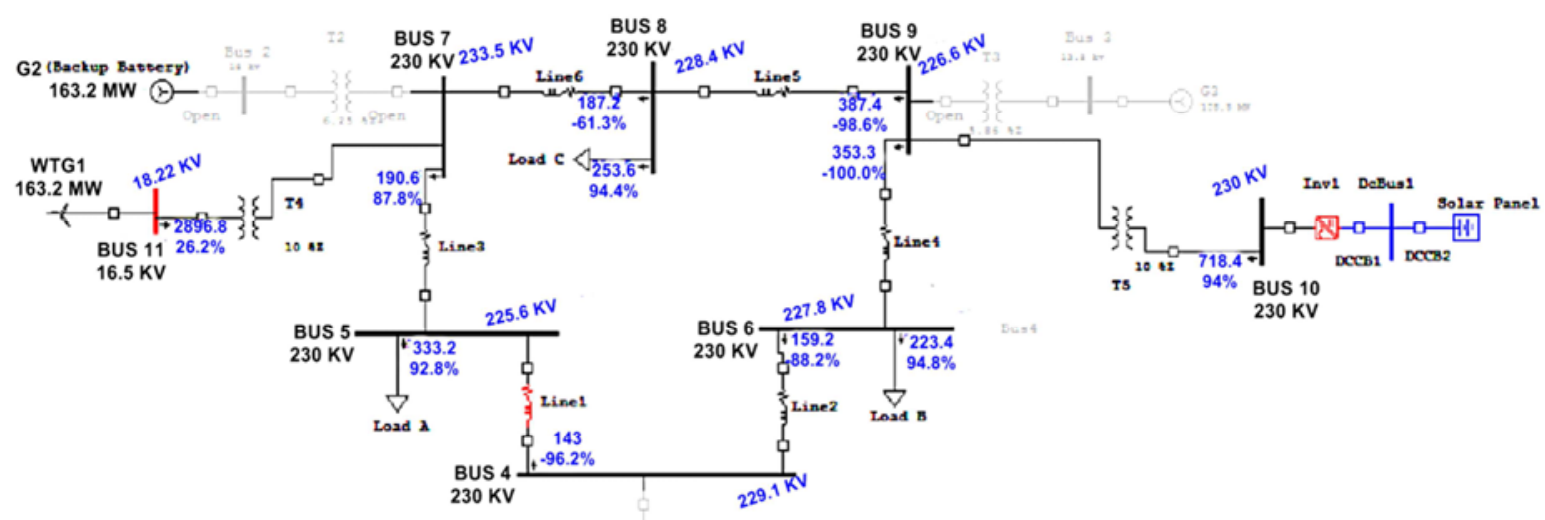

(c) Case-3: Wind turbine and solar PV are active

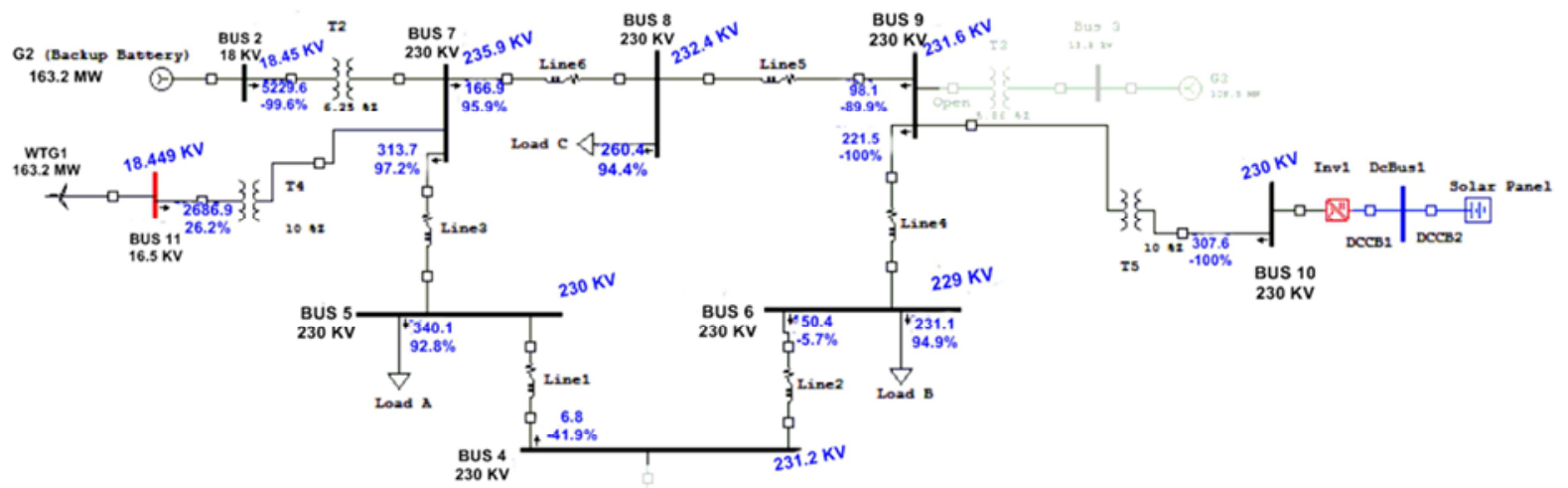

(d) Case-4: Wind, Solar and Battery are active 


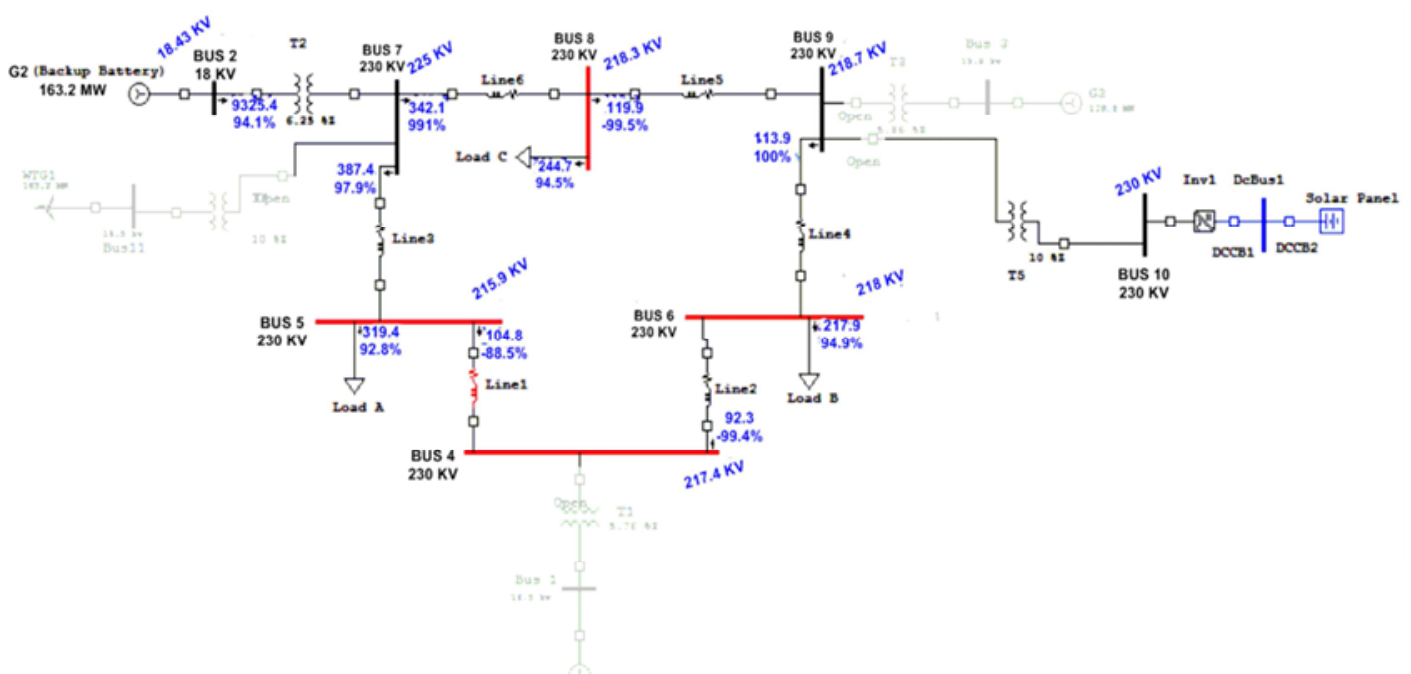

(e) Case-5: Battery is active only

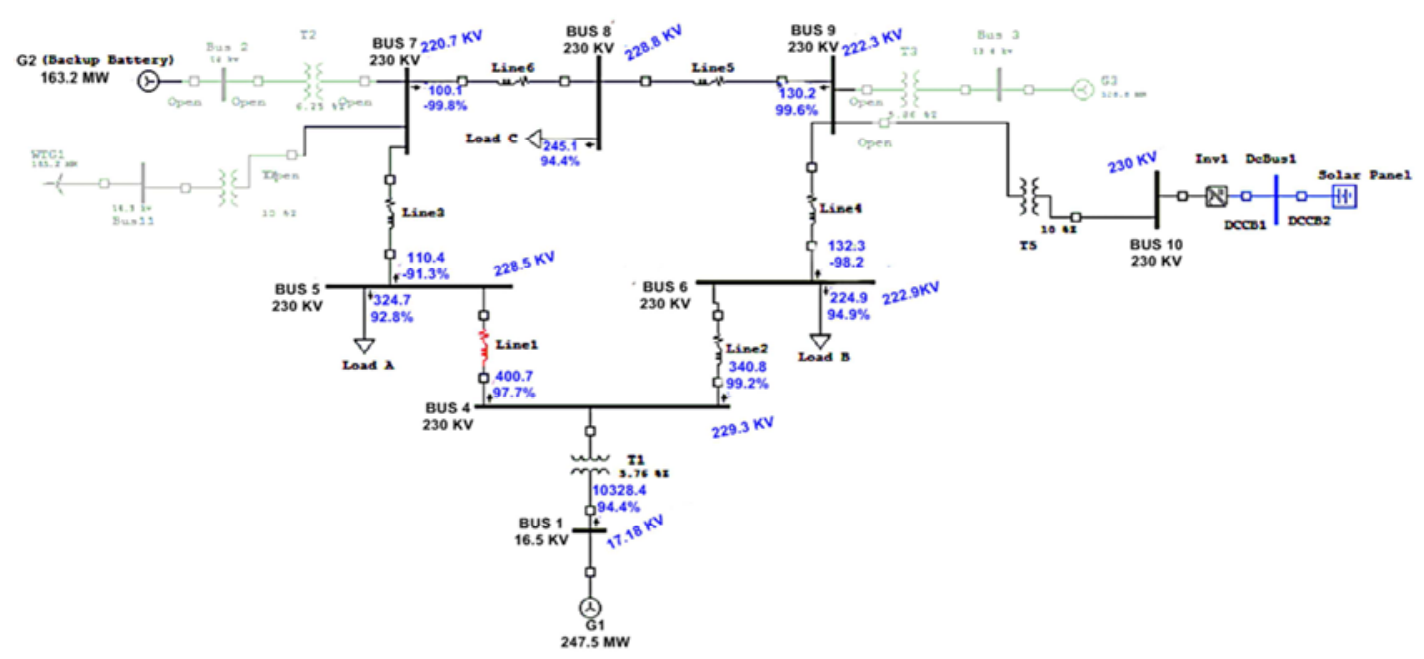

(f) Case-6: Diesel Generator is active only

Figure 4. Steady state analysis of (a) case-1, (b) case-2, (c) case-3, (d) case-4, (e) case-5 and (f) case-6.

Summary of case studies are shown in table below:

Table 1. Summary of case studies.

\begin{tabular}{lccccl}
\hline Cases & WTG & PV Cell & Diesel Gen & Battery & Analysis \\
\hline Case 1 & $\sqrt{ }$ & $\mathrm{X}$ & $\mathrm{X}$ & $\sqrt{ }$ & Bus at wind turbine is overvoltage and transmission line is overloaded \\
Case 2 & $\mathrm{X}$ & $\sqrt{ }$ & $\mathrm{X}$ & $\sqrt{ }$ & The PV system operates with battery bank can maintain required voltage level. \\
Case 3 & $\sqrt{ }$ & $\sqrt{ }$ & $\mathrm{X}$ & $\mathrm{X}$ & The result in this case is almost the same as case-1. One bus is over-voltage and \\
& & & $\mathrm{X} e$ line is overloaded \\
Case 4 & $\sqrt{ }$ & $\mathrm{X}$ & $\sqrt{ }$ & The bus near wind turbine is overvoltage \\
Case 5 & $\mathrm{X}$ & $\mathrm{X}$ & $\mathrm{X}$ & $\sqrt{ }$ & Whole network is suffering from low voltage level. \\
Case 6 & $\mathrm{X}$ & $\mathrm{X}$ & $\mathrm{V}$ & $\mathrm{X}$ & Whole network maintains required voltage profile but one line is overloaded. \\
\hline
\end{tabular}

Generation sources is active marked by $V$, Source is down marked by $X$

Transient Stability Analysis:

Three phase balance fault is applied to the bus connected to generation source in order to analysis the cases of transient stability. The transient stability analysis of hybrid system was studied when the diesel generator (G1) was working as a main generation source not as a backup source. The rejection of any source was simulated as a three phase fault in its bus in order to study the transient stability in such cases. From our simulation, it is clear that the rejection of the solar system doesn't have any negative impact on the system since the wind generator, battery bank and the diesel generator can feed the load. The generator power angle of case 1 is shown figures below (figure -5). And other cases are also shown in subsequent figures (figure 6-8) and analysis was done in latter part. 
Case: 1

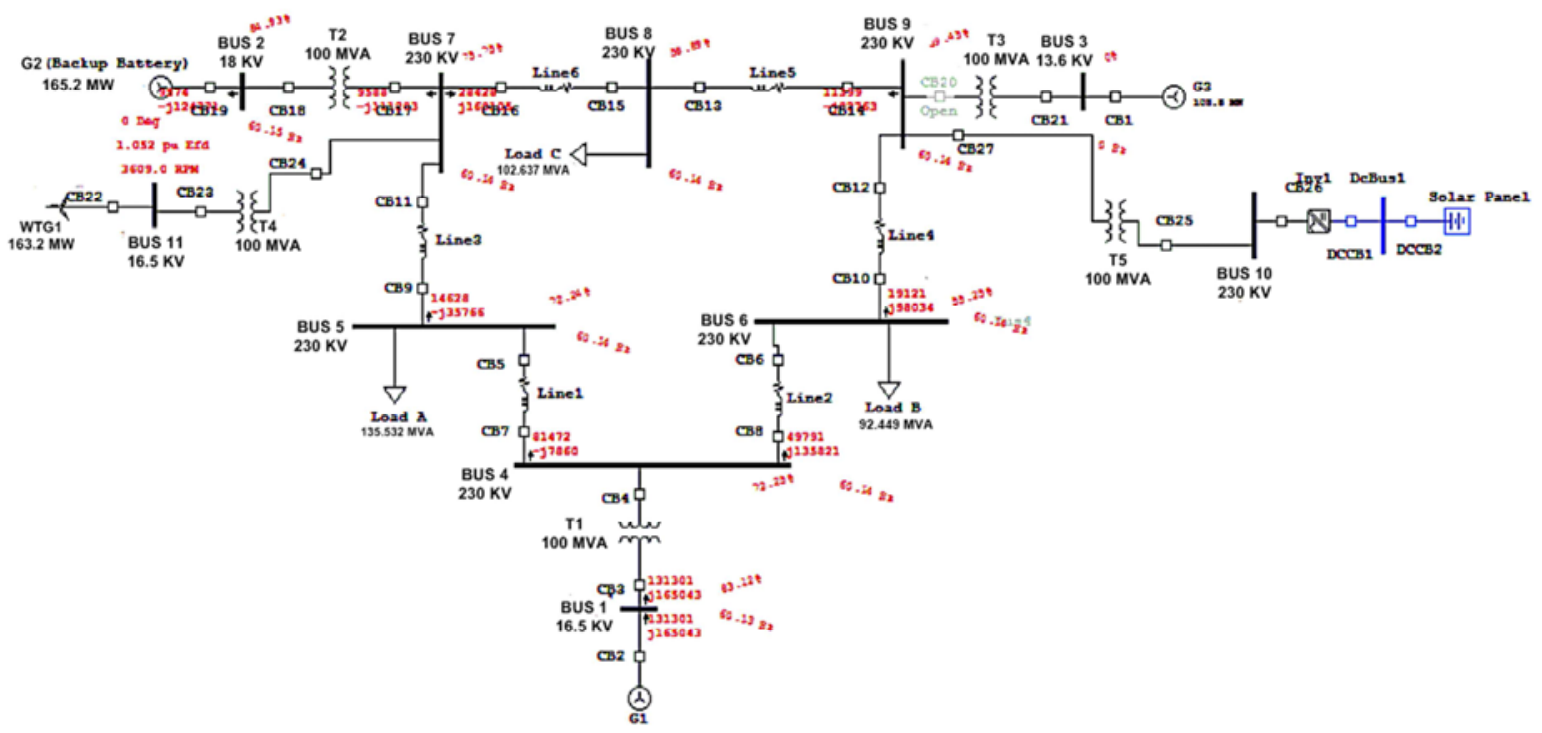

(a)

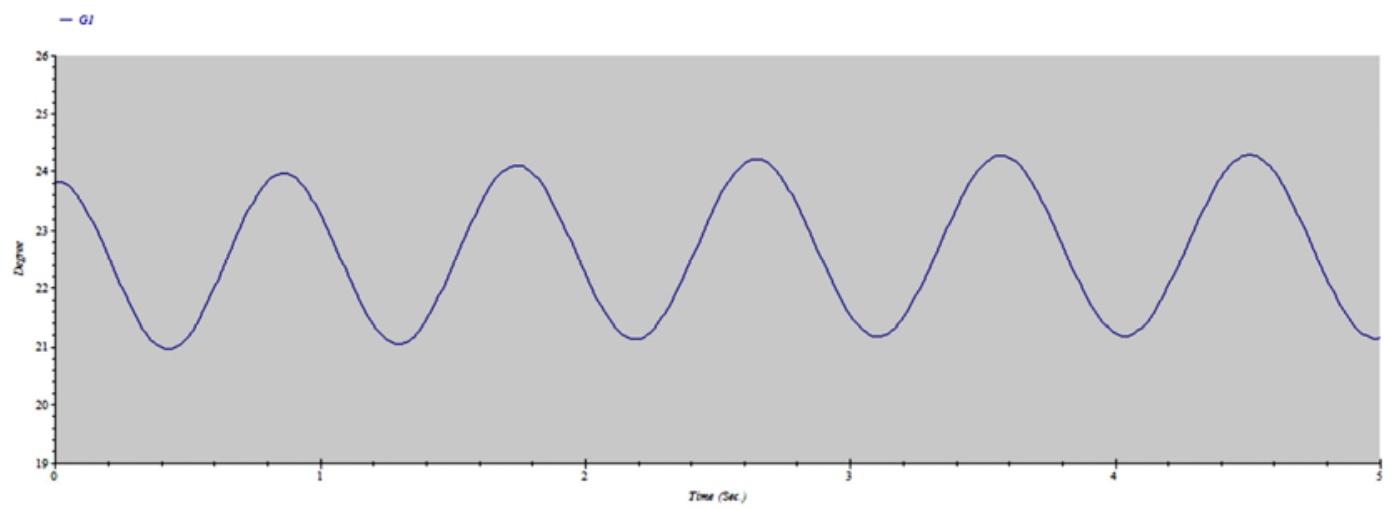

(b)

Figure 5. Case 1: (a) Solar System is down (b) Generator Power Angle for Case-1.

Case -2

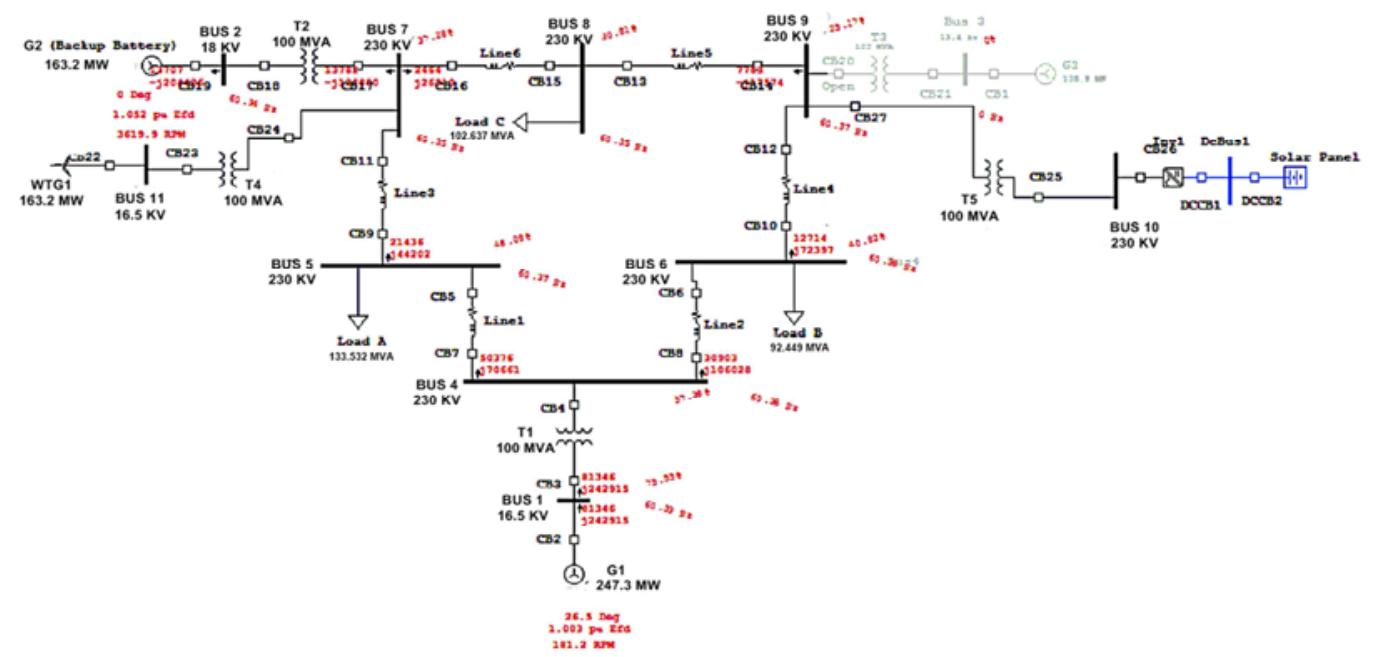




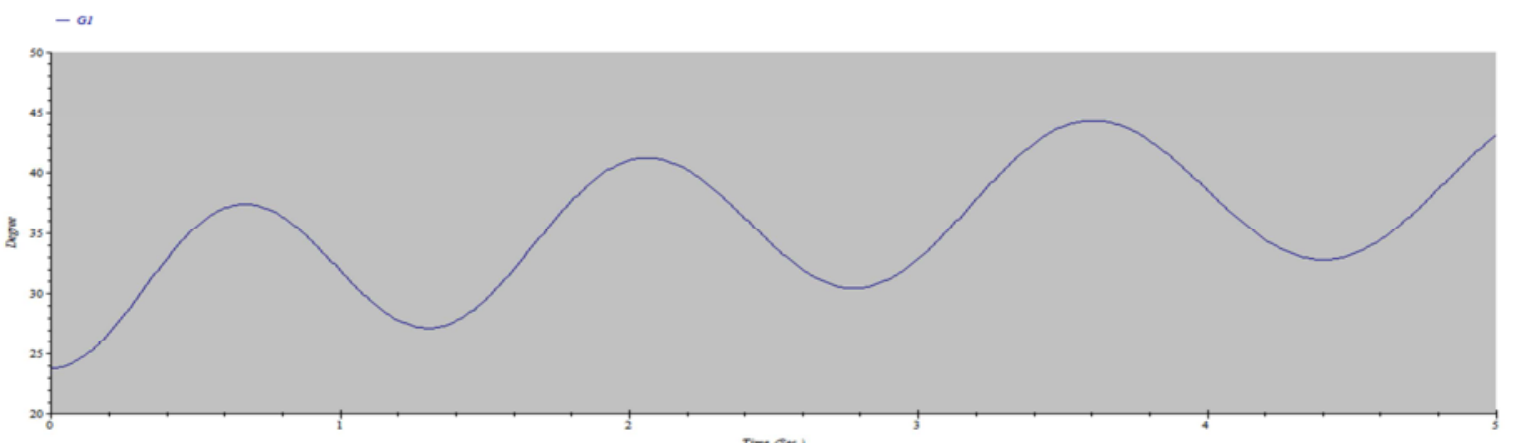

(b)

Figure 6. Case-2: (a) Wind turbine and solar PV are down and (b) Generator Power Angle.

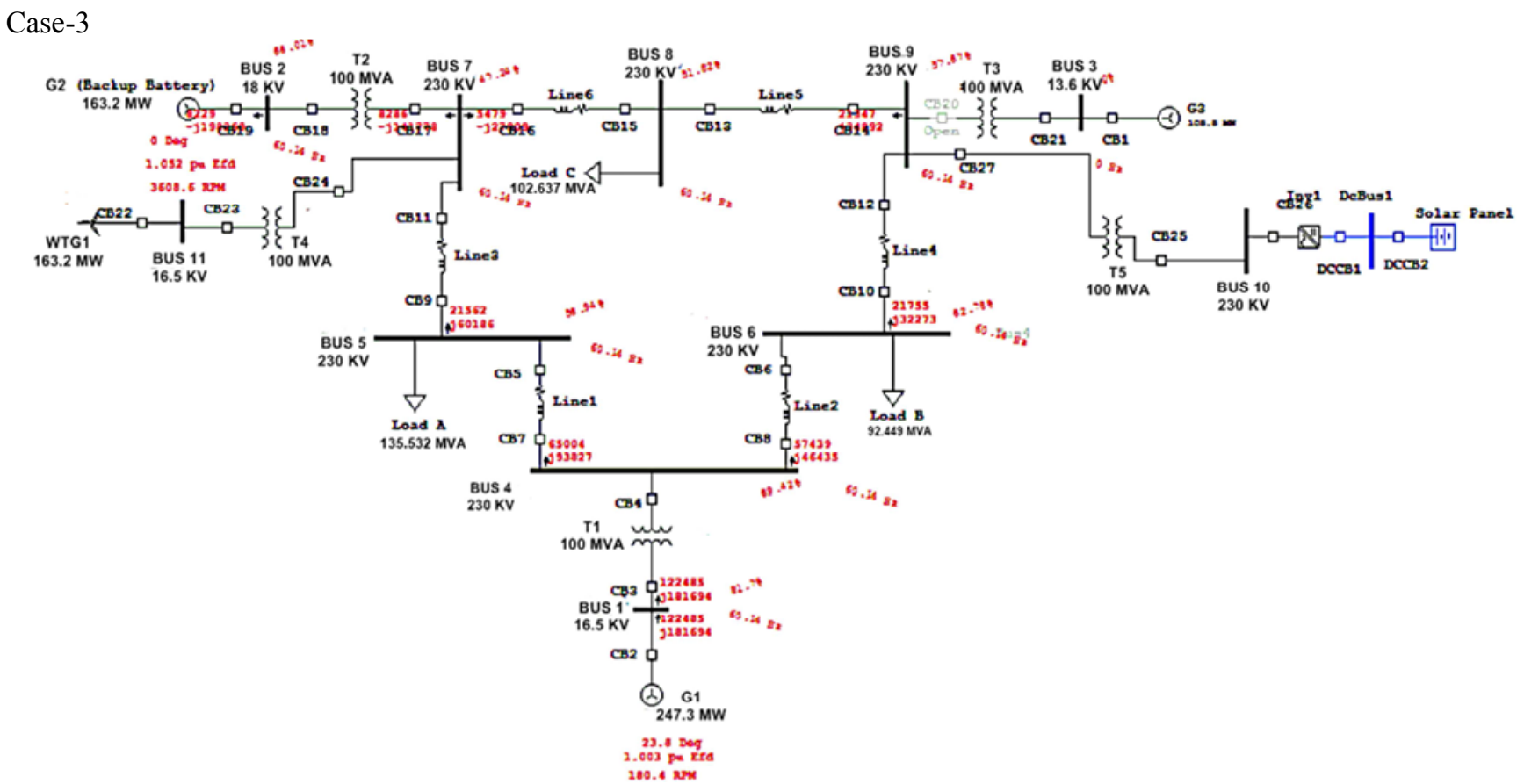

(a)

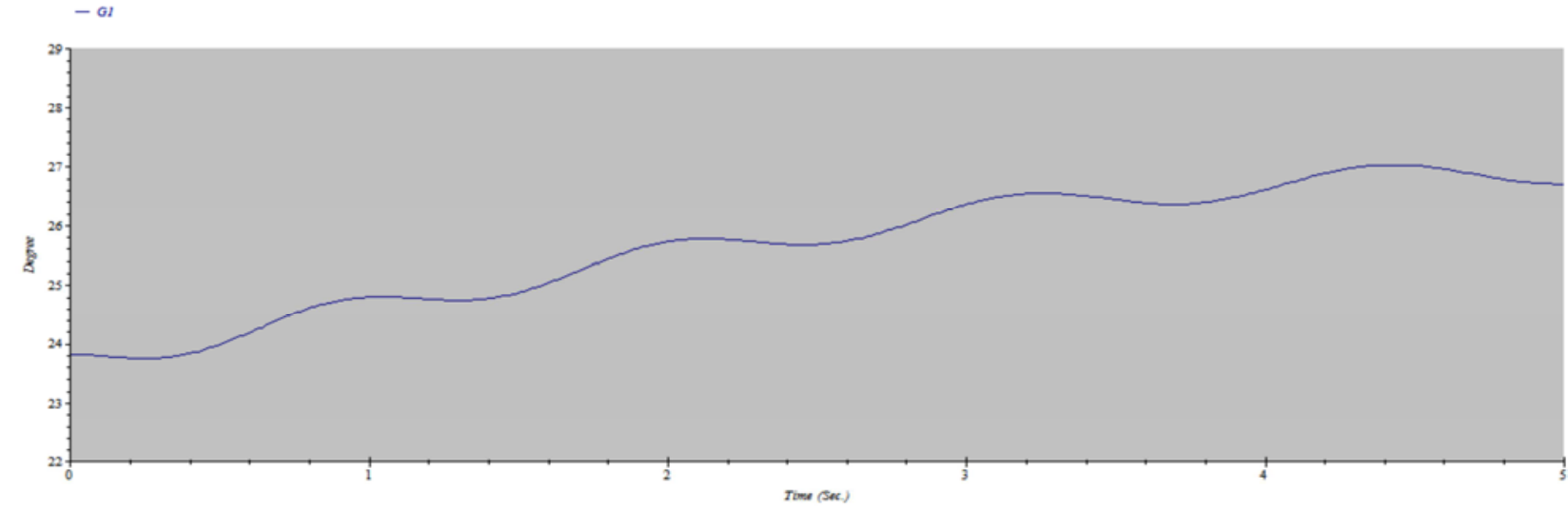

(b)

Figure 7. Case-3 (a) Wind was down (b) Generator Power Angle. 
Case-4:

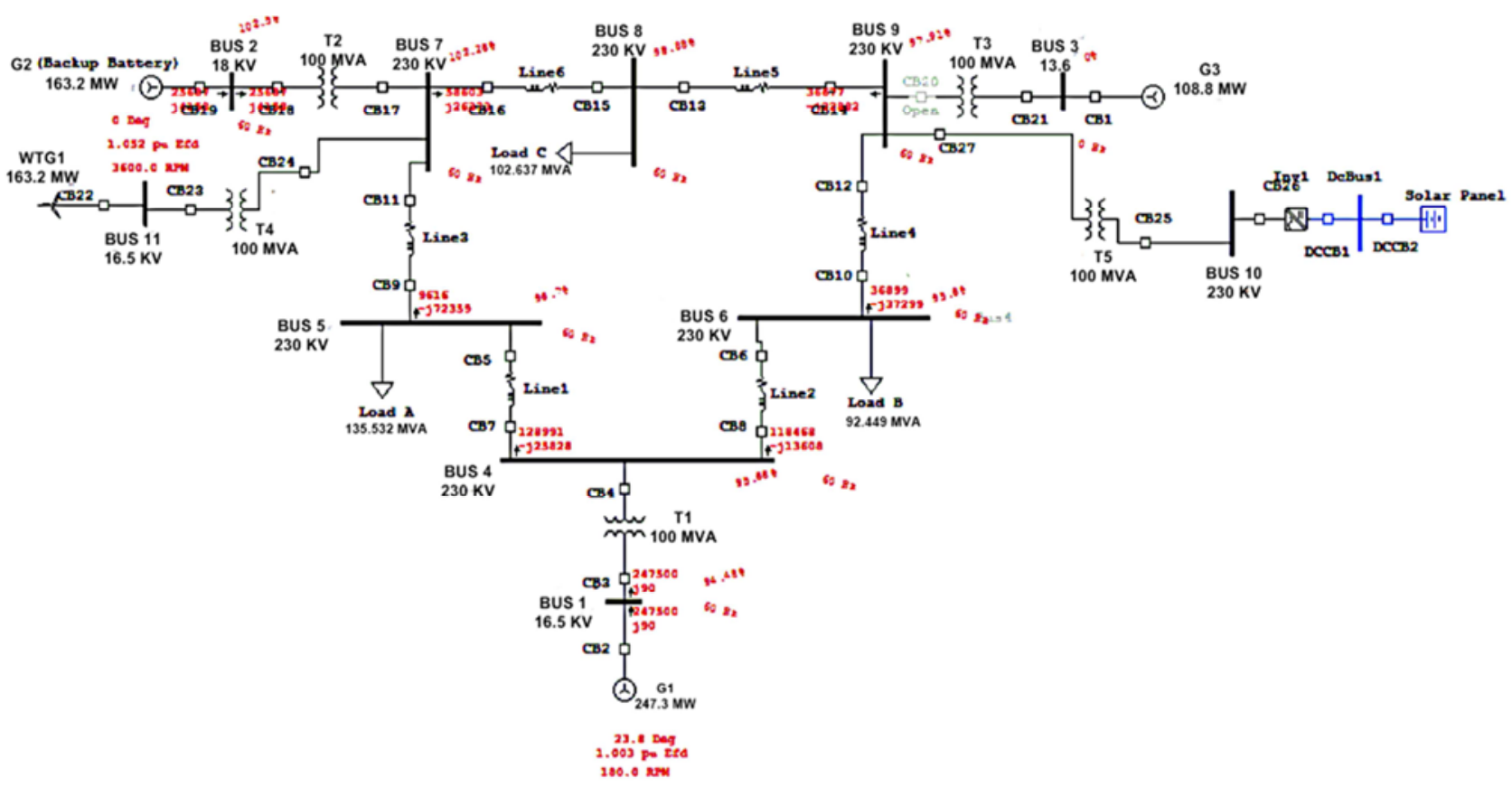

(a)

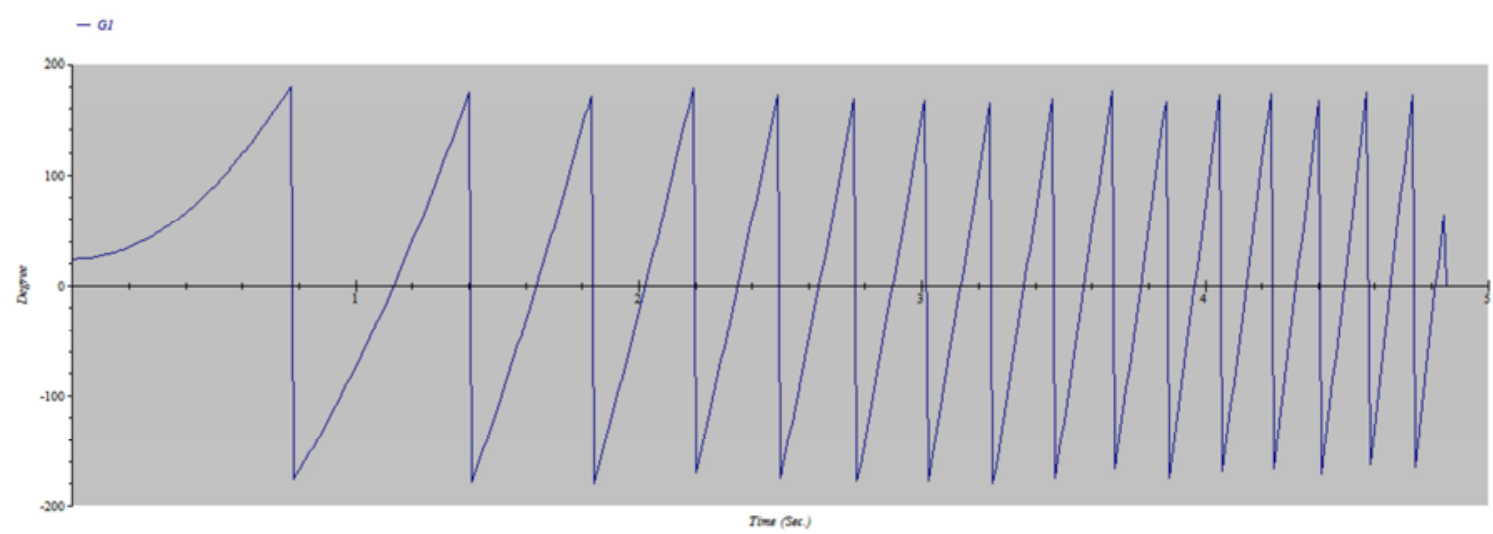

(b)

Figure 8. Case-4: (a) Wind, Solar and the battery are down and (b) Generator Power Angle

Comments on Result:

The transient stability studies are performed in four cases. The summary of transient studies, cases and observations are summarized as follows in table 2:

Table 2. Summary of case studies.

\begin{tabular}{lll}
\hline Cases & Generation down due to fault & Analysis \\
\hline Case 1 & Solar & Solar system doesn't have any negative impact on the system since the wind generator, battery bank and the \\
diesel generator can supply the load.
\end{tabular}

It is seen from the above figures (5-8) that in some cases, due to fault in adjacent bus of generation sources diesel generator suffers rotor angle stability issue. There are several ways to solve this problem. Theoretically and practically, this phenomenon can be resolved by utilizing tap-changer transformer. Another way to solve it is set capacitor bank after close inspection of network. Some lines may face over loading problem. In that case, addition of a parallel line with existing line can improve the system. This problem can also be solved by load sharing between the lines. 


\section{Conclusion}

A hybrid power system consists of Solar PV, Wind turbine, Diesel Generator and energy storage system along with energy conversion system, i.e, converter, has been broadly presented in this report. The whole network based on IEEE 9 Bus system modified and implemented on ETAP software. However, this hybrid system is classified as isolated network. The simulation and analysis have been applied in different combination of operation and fault location. The impact of generation addition and rejection is broadly discussed. Over all study outcome is summarized as the renewable generations (Solar and wind) units have no negative impact on the stability of the system. In this paper, it is also found that hybrid power system including solar and wind generation can meet up the load demand. The ETAP ver. 7 does not provide solar PV symbol, so in that case solar PV system is represented by battery. At present, solar and wind source are available at southern part of Bangladesh. As it said earlier, Hybrid power system can be adopted by remote areas and it's getting more popular due to economic benefit. Isolated networks of remote areas or could be tied to the national grid when large amount of energy is produced. As a continuation of this work, we would like to study the protection coordination problem emerged in hybrid network.

\section{References}

[1] Lazarov VD, Notton G, Zarkov Z, Bochev I. "Hybrid power systems with renewable energy sources types, structures, trends for research and development". In: Proc of International Conference ELMA. 2005.p. 515-20.

[2] Raul Baños, "Optimization methods applied to renewable and sustainable energy: A review", Renewable and Sustainable Energy Reviews 15(4):1753-1766 · May 2011.

[3] A. Kamjoo, A. Maheri and G. A. Putrus, "Reliability criteria in optimal sizing of stand-alone hybrid wind-PV-battery bank system," 2012 2nd International Symposium on Environment Friendly Energies and Applications, Newcastle upon Tyne, 2012, pp. 184-189.

[4] Chemmangot V. Nayar, Mochamad Ashari, W. W. L. Keerthipala: "A grid-interactive photovoltaic uninterruptible power supply system using battery storage and a back up diesel generator", IEEE Transactions on Energy Conversion, Vol. 15, No. 3, September, 2000.

[5] Wichert, B, "PV-Diesel hybrid energy systems for remote area powergeneration - A review of current practice and future developments|"'. Renewable and Sustainable Energy reviews. Volume 1, No. 3, September 1997, pages 209-228.

[6] G. D. Burch, "Hybrid Renewable Energy Systems\|, U.S. Department of Energy", Natural Gas / Renewable Energy Workshops, Colorado, US, 2001.

[7] Klimis Ch. Karasavvas, "Modular simulation of a hybrid power system with diesel, photovoltaic inverter and wind turbine generation”, Journal of Engineering Science and Technology Review 1 (2008) 38-40.

[8] A. Mohammad, "Hybrid Power system generation control", MS thesis, 2012

[9] Dorin Bica, "Isolated hybrid solar-wind-hydro renewable energy system," INTECH, 2014.

[10] Power system stability, available [online]: nptel.ac.in/courses/Webcourse-contents/IIT-KANPUR/powersystem/9/9_1.html

[11] Power system steady state analysis, available [online]: https://www.scribd.com/document/280630426/TRANSIENTSTABILITY

[12] Rotor angle stability, Available [Online]: http://top10 electrical.blogspot.com/2014/04/classification-of-powersystem-stability.html

[13] Transient stability (chapter 9), available [online]: http://www.kau.edu.sa/Files/0056868/Subjects/Chapter\%209. pdf

[14] Swaroop Kumar. Nallagalva, Mukesh Kumar Kirar, Dr. Ganga Agnihotri, "Transient Stability Analysis of the IEEE 9-Bus Electric Power System", IJSET, Volume.1, Issue No.3, pg: 161-166.

[15] NPTEL, Hybrid Systems (chapter 10), available [online]: nptel.ac.in/courses/108108078/pdf/chap10/teach_slides10.pdf

[16] Giorgio Cau, Daniele Cocco, Mario Petrollese, Modeling and Simulation of an Isolated Hybrid Micro-grid with Hydrogen Production and Storage, In Energy Procedia, Volume 45, 2014, Pages 12-21, ISSN 1876-6102.

[17] Muhammad Shahzad Aziz1, UmairSaleem, Ehsan Ali and Khalid Siddiq, "A review on bi-source, off-grid hybrid power generation systems based on alternative energy sources", Journal of Renewable and Sustainable Energy 7, 043142 (2015).

[18] Siemense \& IRENA, "Renewable energy in hybrid mini-grids and isolated grids: economic benefits and business cases", UNEP Collaborating Centre, Germany. 